\title{
Monitoring of in vitro interaction studies of enalapril with hypoglycemic agents by LC-UV
}

This article was published in the following Dove Press journal:

Research and Reports in Medicinal Chemistry

4 February 2013

Number of times this article has been viewed

\author{
Najma Sultana' \\ Safila Naveed ${ }^{1,2}$ \\ M Saeed Arayne ${ }^{3}$ \\ 'Department of Pharmaceutical \\ Chemistry, Faculty of Pharmacy, \\ University of Karachi, Karachi, \\ Pakistan; ${ }^{2}$ Faculty of Pharmacy, Jinnah \\ University for Women, Karachi, \\ Pakistan; ${ }^{3}$ Department of Chemistry, \\ University of Karachi, Karachi, \\ Pakistan
}

\begin{abstract}
The coadministration of antihypertensive and antidiabetic drugs is common, as both of these ailments are synergistic to each other and often occur together. In the present paper, we describe in vitro drug interactions of enalapril, an antihypertensive drug, with the hypoglycemic agents, metformin, glibenclamide, and glimepiride. These studies were carried out using an isocratic reversed phase high-performance liquid chromatographic method using a C18 column with ultraviolet detection at $230 \mathrm{~nm}$. The system was operated at room temperature using a mobile phase consisting of methanol:water (70:30) adjusted to $\mathrm{pH} 2.5$ with o-phosphoric acid with a flow rate of $1 \mathrm{~mL}$ minute ${ }^{-1}$. The assay was reproducible, linear (concentration range of $2.5-100 \mu \mathrm{g} \mathrm{mL}^{-1}$ ) with a correlation coefficient of 0.9999 and an accuracy rate of $98 \%-102 \%$. The results from the reversed phase high-performance liquid chromatographic method clearly indicated that the availability of enalapril was unaffected by the simultaneous administration of hypoglycemic agents. Hence, the two drugs can be safely administered with one another.
\end{abstract}

Keywords: enalapril, antihypertensive agent, hypoglycemic agents, drug interactions, RP-HPLC

\section{Introduction}

Hypertension in diabetics represents an important health problem as the combination of these ailments is common, and can carry significant morbidity and mortality rates in addition to being difficult to treat. The prevalence of hypertension in diabetic people is probably 1.5-2 times higher than in the general population. ${ }^{1}$ Diverse classes of antihypertensive prescriptions may be used for blood pressure management in diabetes; among these, angiotensin II receptor blockers (ARBs), calcium channel blockers, thiazide diuretics, and angiotensin-converting enzyme (ACE) inhibitors are common. ${ }^{2}$ Use of the ACE inhibitor, enalapril, was associated with an increased risk of hypoglycemia (odds ratio, 2.4; 95\% confidence interval [CI], 1.1-5.3) in sulfonylurea users. $^{3}$ Cardiovascular drugs carried a risk of drug-drug interactions (187 drugs, or 49.5\%). The most common potential drug-drug interaction observed was between metformin and enalapril $(n=64) .{ }^{4}$ Use of verapamil, a calcium channel blocker, significantly reduced the risk of developing diabetes. ${ }^{5}$ Similarly, diabetic patients often take antihypertensive medications along with antidiabetic drugs. ${ }^{6}$ The treatment of patients with hypertension and diabetes using ARBs has improved both macro- and microvascular alterations. ${ }^{7}$

Diverse classes of antihypertensive prescriptions may be used for blood pressure management in diabetes; among these, calcium channel blockers, ARBs, thiazide diuretics, and ACE inhibitors are common. Collective pharmacological treatments
Correspondence: Safila Naveed

A 22 Block S, North Nazimabad, Karachi-74600, Pakistan

Fax +92 21366206/4

Email safilal17@yahoo.com
Research and Reports in Medicinal Chemistry 2013:3 I-7

(C) 2013 Sultana et al, publisher and licensee Dove Medical Press Ltd. This is an Open Access article which permits unrestricted noncommercial use, provided the original work is properly cited.
Dovepress

http://dx.doi.org// 0.2147/RRMC.S39643 


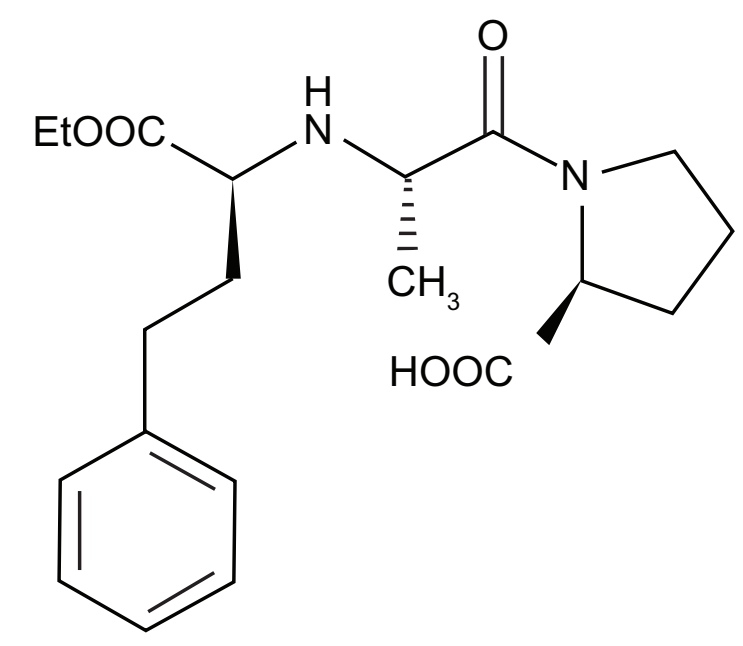

Figure I Chemical structure of enalapril.

generally aim to manage type 2 diabetes mellitus in order to attain satisfactory glucose management and also aim to deal with concomitant pathologies. Drug-drug interactions must be cautiously considered with antihypertensive and hypoglycemic drugs. ${ }^{8}$ A literature survey revealed that the quantification of gliquidone is achieved by ultraviolet (UV) spectrophotometry, ${ }^{9}$ as well as high-performance liquid chromatography (HPLC). ${ }^{10,11}$ Our research group earlier reported methods for the simultaneous determination of rosiglitazone and glimepiride by HPLC, and now this method has been developed and used for interaction studies, ${ }^{12}$ while enalapril and statins have been used as commercial tablets and human serums. ${ }^{13}$ Earlier we reported on the interaction of losartan with gliquidone, as well as pioglitazone and enalapril with $\mathrm{H}_{2}$ receptor antagonist in combined pharmaceutical dosage forms. ${ }^{14,15}$ Combinations of metformin and either glipizide, gliclazide, or glibenclamide are available commercially as single dosage forms. A combination tablet formulation is beneficial in terms of its convenience and rate of patient compliance. The most important purpose of this

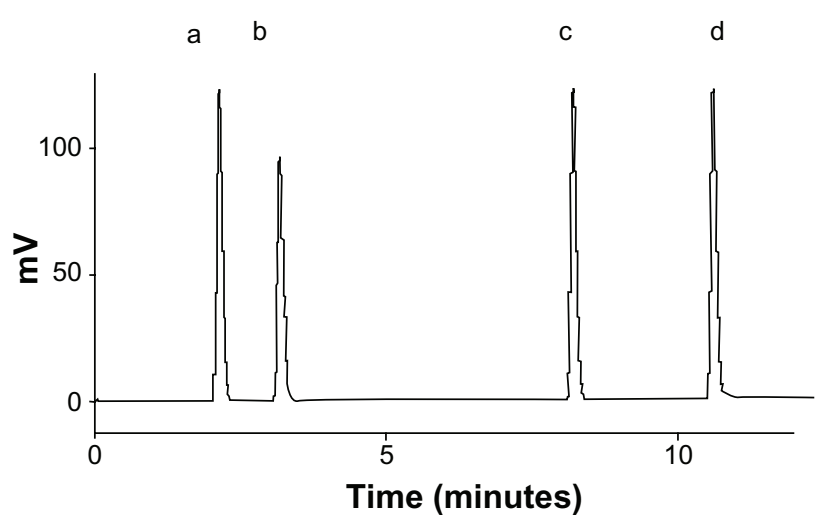

Figure 2 Resolution of metformin, enalapril, glibenclamide, and glimepiride. study was to assess the in vitro drug interaction of enalapril (Figure 1), with commonly prescribed antidiabetic drugs (metformin, glimepiride, and glibenclamide) by utilizing HPLC for the routine monitoring of diabetic patients who take a combination of these medications, and to study the pharmacokinetics of the combined dosage forms.

\section{Aim of study}

Simultaneous determination of these analyses is important for the routine monitoring of diabetic patients who take a combination of medications and for studying the pharmacokinetics of the combined dosage forms.

\section{Methods}

\section{Instrumentation}

A Shimadzu HPLC system (Shimadzu Corporation, Kyoto, Japan) equipped with a liquid chromatography (LC)-10 AT VP pump and an SPD-10 A VP ultravioletvisible spectroscopy (UV-VIS) detector, and another HPLC system (Shimadzu Corporation) equipped with an LC-20AT and SPD-20A UV-VIS detector were utilized. The chromatographic system was integrated via a Shimadzu model CBM-102 to an Intel $^{\circledR}$ Pentium $^{\circledR}$ 4 computer (Intel Corporation, Santa Clara, CA, USA) loaded with Shimadzu CLASS-VP software (version 5.03, Shimadzu Corporation) for data acquisition and mathematical calculations. A Rheodyne ${ }^{\circledR}$ manual injector (model 7725; Chrom Tech, Inc, Apple Valley, MN, USA) was fitted with a $20 \mu \mathrm{L}$ loop, Hypersil ODS C18 column (150 mm $\times 4.6 \mathrm{~mm}, 5$ microns; Thermo Fisher Scientific, Waltham, MA, USA), a Purospher ${ }^{\circledR}$ STAR RP-18 column

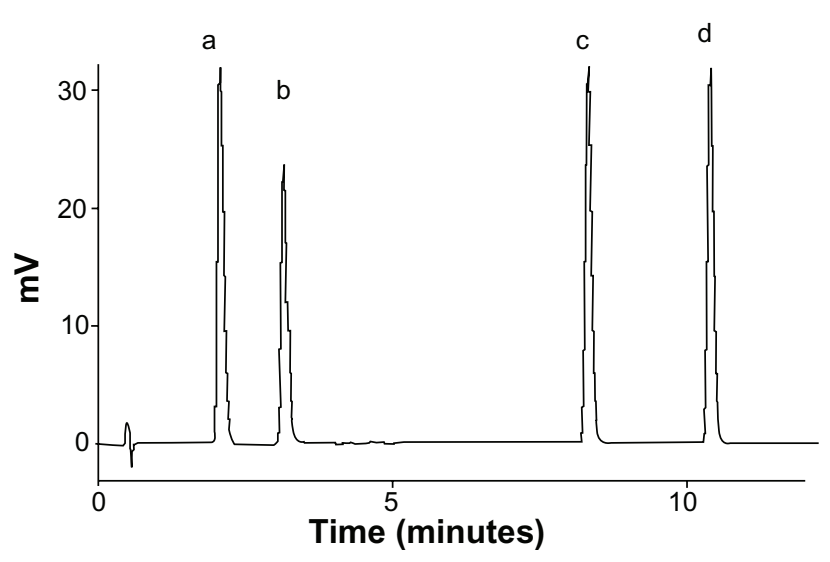

Figure 3 Representative chromatogram of meformin, enalapril, glibenclamide, and glimepiride.

Notes: Representative chromatogram of (a) metformin (2.4 minutes); (b) enalapril (3.7 minutes); (c) glibenclamide (8.3 minutes); and (d) glimepiride (1 I minutes) in mobile phase methanol:water (70:30) and flow rate of $1 \mathrm{~mL} /$ minute $^{-1}$ at $230 \mathrm{~nm}$ in formulations. 
Table I Regression equation

\begin{tabular}{llllll}
\hline Drugs & $\begin{array}{l}\text { Concentration } \\
\left(\mu \mathbf{~ m L}^{-1}\right)\end{array}$ & $\begin{array}{l}\text { Regression } \\
\text { equation }\end{array}$ & $\mathbf{r}^{2}$ & $\begin{array}{l}\text { LOD } \\
\left(\mathbf{n g ~} \mathbf{~ m}^{-1}\right)\end{array}$ & $\begin{array}{l}\text { LOQ } \\
\left(\mathbf{n g ~} \mathbf{~ m L}^{-1}\right)\end{array}$ \\
\hline ENP & $2.5-100$ & $y=2489.4 x+255.5$ & 0.9996 & 1.53 & 4.6 \\
MET & $2.5-100$ & $y=10406 x+24139$ & 0.9993 & 0.317 & 0.96 \\
GLB & $2.5-100$ & $y=14651 x+33832$ & 0.9998 & 0.19 & 0.58 \\
GMP & $2.5-100$ & $y=15438 x+39969$ & 0.9996 & 0.1 & 0.32 \\
\hline
\end{tabular}

Abbreviations: ENP, enalapril; MET, metformin; GLB, glibenclamide; GMP, glimepiride; LOD, limit of detection; LOQ, limit of quantification.

(Merck Millipore, Billerica, MA, USA), and a DGU-14 AM online degasser (Shimadzu Corporation). In addition, a Mettler Toledo electronic balance, microliter syringe, and micropore filtration assembly (Mettler Toledo AG, Greifensee, Switzerland) were used in this study.

\section{Materials and reagents}

Enalapril maleate was a kind gift from Merck \& Co, Inc (Whitehouse Station, NJ, USA); the antidiabetic drugs used in this study were metformin, glimepiride, and glibenclamide, which were from Sanofi-aventis Pakistan Ltd (Karachi, Pakistan), Parke-Davis and Co, Ltd, and Safe Pharmaceutical (Pvt) Ltd (Karachi, Pakistan). All of these drugs had an expiry date of not less than 1 year at the time of the study. All reagents used were of HPLC grade. Acetonitrile, methanol, and phosphoric acid 85\% (Merck, Darmstadt, Germany), and HPLC-grade deionized filtered water were used to prepare the mobile phase. Stock solutions of enalapril and antidiabetic drugs were prepared in the mobile phase. Fresh working solutions were prepared daily. All solutions were filtered through $0.45 \mu \mathrm{m}$ and degassed using a sonicator.

\section{Preparation of solutions}

Standard solutions of enalapril and antidiabetic drugs were prepared by dissolving appropriate amounts of each in mobile phase methanol:water $(70: 30 \mathrm{v} / \mathrm{v}, \mathrm{pH} 2.5)$ to obtain the final drug concentrations of $100 \mu \mathrm{g} \mathrm{mL} \mathrm{m}^{-1}$. For the calibration standards, seven calibrators of each drug were prepared by making serial dilutions from stock solutions. For the assay preparation, the contents of 20 tablets were powdered, and a weighed portion of the powder equivalent to the suitable amount of drug (according to the claims on the labels) was transferred into a $50 \mathrm{~mL}$ volumetric flask. The drug was fully dissolved in the mobile phase, diluted appropriately, and seven dilutions of each drug were prepared - a portion of which was filtered through a disposable $0.45 \mu \mathrm{m}$ filter and then injected to Rheodyne ${ }^{\circledR}$ injector. In case of oral dosage forms, 20 tablets of each drug were crushed, finely powdered, and amounts equivalent to $20 \mathrm{mg}$ of each drug were transferred to separate $100 \mathrm{~mL}$ volumetric flasks, and made up to the mark with respective buffer solutions.

Plasma samples, obtained from healthy volunteers, were collected and stored at $-20^{\circ} \mathrm{C}$. To an aliquot of $1.0 \mathrm{~mL}$ of plasma, $9 \mathrm{~mL}$ of acetonitrile was added and the mixture was vortexed for 1 minute, and centrifuged at 10,000 rpm for 10 minutes. The supernatant was then filtered through a $(0.45 \mu$ pore size membrane filter). An aliquot serum sample was fortified with enalapril and a hypoglycemic agent to get the final concentrations.

Equal volumes of metformin, glimepiride, and glibenclamide were mixed with enalapril to produce final concentrations of $100 \mu \mathrm{g} \mathrm{mL}^{-1}$ in reaction flasks. These flasks were kept in a water bath at a constant temperature $\left(37^{\circ} \mathrm{C}\right)$ with constant stirring. A total of $2 \mathrm{~mL}$ of aliquot was drawn from the reaction flask at 0 minutes, and periodically after 15 -minute time intervals for 2 hours. Aliquots that were withdrawn were diluted to $10 \mathrm{~mL}$ with methanol, filtered through a Millipore filter (0.45 $\mu \mathrm{M}$; Merck Millipore), and chromatographed.

\section{Results and discussion Method validation}

This newly developed method has been validated and holds well for the determination of these drugs in raw materials,

Table 2 Accuracy in formulations

\begin{tabular}{|c|c|c|c|c|c|c|c|c|}
\hline \multirow{2}{*}{ 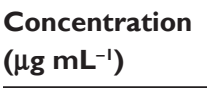 } & \multicolumn{2}{|l|}{ ENP } & \multicolumn{2}{|l|}{ MET } & \multicolumn{2}{|l|}{ GLP } & \multicolumn{2}{|l|}{ GMP } \\
\hline & $\%$ RSD & $\%$ rec & $\%$ RSD & $\%$ rec & $\%$ RSD & $\%$ rec & $\%$ RSD & \% rec \\
\hline 80 & 0.011 & 101 & 0.002 & 100.9 & 0.002 & 99.9 & 0.08 & 100 \\
\hline 100 & 0.326 & 100.3 & 0.001 & 100.5 & 0.001 & 100 & 0.002 & 100.2 \\
\hline 120 & 0.001 & 100 & 0.008 & 99.7 & 0.008 & 99.7 & 0.001 & 100.1 \\
\hline
\end{tabular}

Abbreviations: ENP, enalapril; MET, metformin; GLP, glibenclamide; GMP, glimepiride; RSD, relative standard deviation; rec, recovery. 
Table 3 Intraday and interday precision of the method

\begin{tabular}{|c|c|c|c|c|c|c|c|c|}
\hline \multirow[t]{2}{*}{ Concentration } & \multicolumn{4}{|c|}{ Intraday (\% recovery) } & \multicolumn{4}{|c|}{ Interday (\% recovery) } \\
\hline & ENP & MET & GLB & GMP & ENP & MET & GLB & GMP \\
\hline \multicolumn{9}{|l|}{ Bulk material } \\
\hline 2.5 & 100.9 & 100.9 & 100 & 98.85 & 97.44 & 97.4 & 97.6 & 99.2 \\
\hline 5 & I0I.I & 101.1 & 101 & 99.5 & 100.5 & 102 & 100.8 & 102 \\
\hline 10 & 99.49 & 100.9 & 101 & 100.55 & 99.87 & 99.5 & 100 & 100 \\
\hline 25 & 101.2 & 100.5 & 101 & 101.19 & 99.2 & 101 & 102 & 102 \\
\hline 50 & 98.94 & 99.45 & 99.1 & 98.14 & 100.8 & 101 & 100.2 & 100.1 \\
\hline 100 & 101.1 & 100.6 & 99.6 & 99.58 & 99.92 & 100 & 101.8 & 101.6 \\
\hline \multicolumn{9}{|l|}{ Serum } \\
\hline 2.5 & 100.8 & 99.9 & 99.9 & 100.2 & 98.5 & 98.4 & 97.6 & 100 \\
\hline 5 & 101 & 100.2 & 99.8 & 100.02 & 100.5 & 102 & 101.2 & 101.2 \\
\hline 10 & 100.4 & 100.2 & 99.8 & 100.55 & 99.87 & 99.5 & 100 & 98.7 \\
\hline 25 & 101.2 & 101.2 & 99.9 & 101.19 & 100.2 & 101 & 100.3 & 98.8 \\
\hline 50 & 99.94 & 98.9 & 99.1 & 99.8 & 100.8 & 101 & 100.2 & 98.9 \\
\hline 100 & 100.1 & 101.2 & 99.6 & 99.58 & 100.3 & 100 & 100.2 & 99.9 \\
\hline
\end{tabular}

Abbreviations: ENP, enalapril; MET, metformin; GLB, glibenclamide; GMP, glimepiride.

dosage formulations, and human serum. For validation of the analytical method, the guidelines of the International Conference on the Harmonization of Technical Requirements for the Registration of Pharmaceuticals for Human Use were followed, where they recommended the accomplishment of selectivity, specificity, linearity, accuracy of tests, precision, sensitivity, limit of detection, and quantification of the method.

\section{Selectivity and specificity}

The selectivity and specificity of the method was established through the study of the resolution factor at the peak of enalapril from medications used in noninsulin-dependent diabetes mellitus. The method demonstrated good resolutions and was found to be free of interference from excipients (Figure 2) used in formulation products, and thus the method is specific for enalapril and noninsulin-dependent diabetes mellitus drugs (Figure 3).

\section{Range and linearity}

Linearity is generally reported as the variance of the slope of the regression line. Linearity was tested with known concentrations of enalapril, metformin, glibenclamide, and glimepiride (ie, 2.5, 5, 10, 25, 50, and

Table 4 Robustness of the method $(n=6)$

\begin{tabular}{|c|c|c|c|c|}
\hline & Level & $\mathbf{K}^{\prime}$ & $\mathbf{T}$ & $\left(\mathbf{R}_{\mathrm{s}}\right)$ \\
\hline \multicolumn{5}{|c|}{ A: pH of mobile phase } \\
\hline $2.6^{\prime}$ & -0.2 & 4.8 & 1.39 & 2.4 \\
\hline 2.8 & 0 & 4.5 & 1.43 & 2.3 \\
\hline 3 & 0.2 & 4.2 & 1.4 & 2.2 \\
\hline Mean \pm SD $(n=6)$ & & $4.5 \pm 0.3$ & $1.43 \pm 0.020$ & $2.3 \pm 0.1$ \\
\hline \multicolumn{5}{|c|}{ B: flow rate $\left(\mathrm{mL} \mathrm{min}^{-1}\right)$} \\
\hline 0.8 & -0.2 & 4.1 & 1.45 & 2.32 \\
\hline I & 0 & 4.3 & 1.44 & 2.36 \\
\hline 1.2 & 0.2 & 4.4 & 1.42 & 2.37 \\
\hline Mean \pm SD $(n=6)$ & & $4.3 \pm 0.212$ & $1.44 \pm 0.015$ & $2.36 \pm 0.026$ \\
\hline \multicolumn{5}{|c|}{ C: percentage of water in mobile phase (V/V) } \\
\hline 25 & -5 & 4.6 & 1.42 & 2.38 \\
\hline 30 & 0 & 4.3 & 1.43 & 2.36 \\
\hline 35 & 5 & 4.5 & 1.46 & 2.33 \\
\hline Mean $\pm \operatorname{SD}(n=6)$ & & $4.36 \pm 0.070$ & $2.36 \pm 0.025$ & $2.36 \pm 0.025$ \\
\hline \multicolumn{5}{|c|}{ D: wavelength (nm) } \\
\hline 225 & -5 & 4.5 & 1.42 & 2.38 \\
\hline 230 & 0 & 4.3 & 1.43 & 2.36 \\
\hline 235 & 5 & 4.4 & 1.45 & 2.32 \\
\hline Mean \pm SD $(n=6)$ & & $4.3 \pm 0.070$ & $1.43 \pm 0.015$ & $2.36 \pm 0.030$ \\
\hline
\end{tabular}

Abbreviations: $n$, theoretical plates; $K^{\prime}$, capacity factors; $T$, tailing factor; $R$, resolution; SD, standard deviation; $V$, volume. 
Table 5 Ruggedness of the method

\begin{tabular}{|c|c|c|c|c|c|c|}
\hline \multicolumn{3}{|c|}{ HPLC system } & \multicolumn{2}{|l|}{ LC IO } & \multicolumn{2}{|l|}{ LC 20} \\
\hline Drugs & Columns & $\begin{array}{l}\text { Concentration } \\
\left(\mu \mathrm{g} \mathrm{mL}^{-1}\right)\end{array}$ & Found $\left(\mu \mathrm{g} \mathrm{mL}^{-1}\right)$ & Recovery (\%) & Found $\left(\mu \mathrm{g} \mathrm{mL}^{-1}\right)$ & Recovery (\%) \\
\hline \multirow[t]{6}{*}{ ENP } & Hypersil ODS & 8 & 8.03 & 100.3 & 8.06 & 100.9 \\
\hline & & 10 & 9.99 & 99.9 & 9.98 & 99.99 \\
\hline & & 12 & 12 & 99.98 & 12 & 99.89 \\
\hline & Purospher STAR & 8 & 7.99 & 100 & 8.3 & 101 \\
\hline & & 10 & 9.83 & 100 & 10.3 & 101.3 \\
\hline & & 12 & 12 & 100.3 & 12.22 & 102 \\
\hline \multirow[t]{6}{*}{ MET } & Hypersil ODS & 8 & 8.4 & 100.9 & 8.3 & 100.9 \\
\hline & & 10 & 9 & 100.5 & 9.98 & 99.99 \\
\hline & & 12 & 11.9 & 99.7 & 11.9 & 99.89 \\
\hline & Purospher STAR & 8 & 7.99 & 100 & 8.6 & 101 \\
\hline & & 10 & 10 & 101 & 10.3 & 100 \\
\hline & & 12 & 12.3 & 100.3 & 12.3 & 102 \\
\hline \multirow[t]{6}{*}{ GLB } & Hypersil ODS & 8 & 7.98 & 99.9 & 8.06 & 100.9 \\
\hline & & 10 & 9.99 & 100 & 9.99 & 100 \\
\hline & & 12 & 11.98 & 99.7 & 11.9 & 99.8 \\
\hline & Purospher STAR & 8 & 7.99 & 100.9 & 8.9 & 101 \\
\hline & & 10 & 10.36 & I0I.I & 9.99 & 100 \\
\hline & & 12 & 11.39 & 99.49 & 12.9 & 102 \\
\hline \multirow[t]{6}{*}{ GMP } & Hypersil ODS & 8 & 7.98 & 99.7 & 8.9 & 102 \\
\hline & & 10 & 9.99 & 100.2 & 9.98 & 100 \\
\hline & & 12 & 12 & 100.1 & 11.9 & 99.9 \\
\hline & Purospher STAR & 8 & 7.99 & 100.9 & 8.9 & 101 \\
\hline & & 10 & 10.3 & I0I.I & 10.9 & 101 \\
\hline & & 12 & 11.9 & 99.49 & 12.22 & 101 \\
\hline
\end{tabular}

Notes: Hypersil ODS: Thermo Fisher Scientific, Waltham, MA, USA. Purospher ${ }^{\circledR}$ STAR: Merck Millipore, Billerica, MA, USA.

Abbreviations: HPLC, high-performance liquid chromatography; LC, liquid chromatography; ENP, enalapril; MET, metformin; GLB, glibenclamide; GMP, glimepiride.

$100 \mu \mathrm{g} \mathrm{mL} \mathrm{m}^{-1}$, respectively). Five runs were performed for every concentration. Injected concentrations versus peak area were plotted, and the correlation coefficients were calculated, which are shown in Table 1.

\section{Accuracy and recovery}

The accuracy or closeness levels of the measured values were evaluated and compared to the true as the percentage of relative error between the measured mean concentrations and the taken concentrations in order to ascertain whether the method is capable of measuring all the taken amount or not. The difference in these is accounted for in relative standard deviation (RSD). A minimum of three concentration levels covering the specified ranges were selected and three runs were performed for every concentration; the peak area was then calculated, as given in Table 2.

\section{Precision}

The intra- and interday precision was evaluated by assaying the samples (Table 3). In this assay, the intraday precision and the interday precision recovery was $98 \%-102 \%$ in bulk materials and in human serum. Intra- and interday precision was performed and the percentage of RSD was found to be less than $2 \%$, which indicates that the method was sufficiently accurate and precise.

\section{Robustness}

Robustness of the method was accomplished by design modifications made to the method parameters such as composition, flow rate, $\mathrm{pH}$ of the mobile phase, detection wavelength, injection volume, and column temperature

Table 6 Percentage availability of enalapril and antidiabetic drugs

\begin{tabular}{lllllll}
\hline $\begin{array}{l}\text { Time } \\
\text { (minutes) }\end{array}$ & ENP & MET & ENP & GLB & ENP & GMP \\
\hline 0 & 99.89 & 100.01 & 100.34 & 100.34 & 102 & 99.99 \\
30 & 99.65 & 99.02 & 99.54 & 99.54 & 101.3 & 100 \\
60 & 100.23 & 95.31 & 98.12 & 98.99 & 102.3 & 101 \\
90 & 101.61 & 105.56 & 99.69 & 99.69 & 102.3 & 102.3 \\
120 & 100.2 & 98.3 & 98.46 & 98.46 & 101.2 & 102 \\
150 & 101.98 & 98.88 & 100.3 & 100.63 & 102.3 & 103 \\
180 & 106.46 & 99.99 & 100.36 & 100.36 & 102.3 & 104.3 \\
\hline
\end{tabular}

Abbreviations: ENP, enalapril; MET, metformin; GLB, glibenclamide; GMP, glimepiride. 
(Table 4), and it was found that the percentage of RSD values did not exceed more than $2 \%$.

\section{Ruggedness}

The ruggedness of the study was established by determining enalapril, metformin, glibenclamide, and glimepiride using the same and different chromatographic systems by using two different columns. The assay results indicated that the method was capable with high precision (Table 5).

\section{Limit of detection and quantification}

The detection limit of an individual analytical procedure is the lowest amount of analyte in a sample which can be detected, but not necessarily quantitated as an exact value. The quantitation limit of an individual analytical procedure is the lowest amount of analyte in a sample which can be quantitatively determined with suitable precision and accuracy. The limit of detection and limit of quantification are calculated and given in Table 1 .

\section{Interaction studies using HPLC}

Results of these interactions are summarized in Table 6 . The percentage of availability of enalapril and metformin was found to be between $98 \%-106 \%$, indicating that there was no reaction between the two drugs. These results clearly indicated that enalapril could be safely coadministered with metformin. The two drugs did not inhibit or disturb the absorption of each other. Similar behavior was observed with glibenclamide and glimepiride; the availability of enalapril was found to be between $102 \%$ and $103 \%$ with glibenclamide and glimepiride, and the availability of glibenclamide and glimepiride remained almost unchanged. No remarkable change in the area under the curve and drift in retention time were observed; however, the results showed that no interaction occurred as the percent of recovery remained almost unchanged.

\section{Conclusion}

A liquid chromatographic method for the simultaneous quantitation of enalapril with metformin, as well as glibenclamide and glimepiride was developed and utilized for the monitoring of in vitro interaction studies of enalapril with these hypoglycemic drugs. It has been concluded that the current method is fast and easy to perform, has low limit of detection and quantification values, shows a high percentage of recoveries, and is linear up to a wide range of concentrations. Moreover, on the basis of the interaction results obtained from HPLC technique, it is concluded that no interaction occurred between metformin, glibenclamide, and glimepiride with enalapril.

\section{Disclosure}

The authors report no conflicts of interest in this work.

\section{References}

1. Pickup JC, Williams G. Hypertension and diabetes mellitus. In: Pickup JC, Williams, G, editors. Textbook of Diabetes. Oxford, UK: Blackwell Science Inc; 1991:719-720.

2. Triplitt C. Drug interactions of medications commonly used in diabetes. Diabetes Spectr. 2006;19(4):202-211.

3. Thamer M, Ray NF, Taylor T. Association between antihypertensive drug use and hypoglycemia: a case-control study of diabetic users of insulin or sulfonylureas. Clin Ther. 1999;21(8):1387-1400.

4. Dinesh KU, Subish P, Pranaya M, Shankar PR, Anil SK, Durga B. Pattern of potential drug-drug interactions in diabetic out-patients in a tertiary care teaching hospital in Nepal. Med J Malaysia. 2007;62(4): 294-298.

5. Ross MF. Certain blood pressure-lowering drugs reduce diabetes risk in Hispanic patients. University of Florida News. Gainesville, FL: University of Florida; 2006. Available from: http://news.ufl. edu/2006/05/22/hispanic/. Accessed January 23, 2013.

6. Leichter SB, Thomas S. Combination medications in diabetes care: an opportunity that merits more attention. Clin Diabetes. 2003;21(4): 175-178.

7. Dahlöf B, Devereux RB, Kjeldsen SE, et al; LIFE Study Group. Cardiovascular morbidity and mortality in the Losartan Intervention For Endpoint reduction in hypertension study (LIFE): a randomised trial against atenolol. Lancet. 2002;359(9311):995-1003.

8. Scheen AJ. Drug interactions of clinical importance with antihyperglycaemic agents: an update. Drug Saf. 2005;28(7):601-631.

9. Arayne MS, Sultana N, Mirza AZ. Spectrophotometric method for quantitative determination of gliquidone in bulk drug, pharmaceutical formulations and human serum. PakJ Pharm Sci. 2006;19(3):185-189.

10. von Nicolai H, Brickl R, Eschey H, et al. Duration of action and pharmacokinetics of the oral antidiabetic drug gliquidone in patients with non-insulin-dependent (type 2) diabetes mellitus. Arzneimittelforschung. 1997;47(3):247-252.

11. Sridevi S, Diwan PV. Validated HPLC method for the determination of gliquidone in rat plasma. Pharmacy and Pharmacology Communications. 2000;6(7):303-307.

12. Jingar JN, Rajput SJ, Dasandi B. Development and validation of LC-UV for simultaneous estimation of rosiglitazone and glimepiride in human plasma. Chromatographia. 2008;67(11-12):951-955.

13. Sultana N, Arayne MS, Safila N. Simultaneous determination of enalapril and statins in pharmaceutical formulations by RP-HPLC. Journal of Chilean Chemical Society. 2011;56(3):734-737.

14. Mirza AZ, Arayne MS, Sultana N, Qureshi F. Spectroscopic study to characterize in vitro interaction of losartan with gliquidone and pioglitazone. Med Chem Res. 2012;22(1):351-359.

15. Sultana N, Arayne MS, Safila N, Shamshad H. An RP-HPLC method for simultaneous analysis and interaction of enalapril maleate with H2-receptor antagonists. Acta Chromatographica. 2009; 214:547-558. 
Research and Reports in Medicinal Chemistry

Dovepress

\section{Publish your work in this journal}

Research and Reports in Medicinal Chemistry is an international, peerreviewed, open access journal publishing original research, reports, reviews and commentaries on all areas of medicinal chemistry. The manuscript management system is completely online and includes a very quick and fair peer-review system, which is all easy to use.

Submit your manuscript here: http://www.dovepress.com/research-and-reports-in-medicinal-chemistry-journal
Visit http://www.dovepress.com/testimonials.php to read real quotes from published authors. 